Annales Geophysicae (2001) 19: 351-358 C European Geophysical Society 2001

\title{
An interpretation of ion composition diurnal variation deduced from EISCAT observations
}

\author{
A. V. Mikhailov ${ }^{1}$ and W. Kofman ${ }^{2}$ \\ ${ }^{1}$ Institute of Terrestrial Magnetism, Ionosphere and Radio Wave Propagation 142090, Troitsk, Moscow Region, Russia \\ ${ }^{2}$ Laboratoire de Planétologie de Grenoble, Bâtiment D de Physique B. P. 53, 38041 Grenoble Cedex 9, France
}

Received: 9 June 2000 - Revised: 16 November 2000 - Accepted: 15 January 2001

\begin{abstract}
Physical interpretation is made of the $\mathrm{O}^{+} / \mathrm{Ne}$ diurnal variations in summer, revealed by Litvine et al. (1998) from the EISCAT observations. It is shown that the observed anti-correlation between the $Z_{50}$ parameter, corresponding to the transition region between $50 \%$ of molecular and atomic ions, and the width $D_{z}$ of the transition, defined as the altitude width between $10 \%$ and $90 \%$ of the $\mathrm{O}^{+} / \mathrm{Ne}$ ratio, can be reproduced in model calculations and the result of different recombination laws (quadratic in the lower and linear in the upper ionosphere) as well as diurnal variations in the photoionization rates.
\end{abstract}

Key words. Ionosphere (ion chemistry and composition; modeling and forecasting)

\section{Introduction}

Relative ion composition $\left(\mathrm{O}^{+} / \mathrm{Ne}\right.$ ratio) deduced from EISCAT observations demonstrates diurnal variations as was depicted by Lathuillère and Pibaret (1992) and Litvine et al. (1998). The $Z_{50}$ parameter, corresponding to the transition region between $50 \%$ of molecular and atomic ions, and the width $D_{z}$ of the transition, defined as the altitude width between $10 \%$ and $90 \%$ of the $\mathrm{O}^{+} / \mathrm{Ne}$ ratio, correlate in their diurnal variations during winter and equinoctial periods with $Z_{50}$ and $D_{z}$ being the smallest around noon hours and the largest around midnight. Such variations are typical of winter and equinoctial periods and they were revealed in the earlier ion composition model by Lathuillère and Pibaret (1992). On the contrary, $Z_{50}$ and $D_{z}$ anti-correlate in their diurnal variations for the summer period both at solar maximum and minimum, as it was shown for the first time by Litvine et al. (1998). This peculiarity of summer $\mathrm{O}^{+} / \mathrm{Ne}$ variations needs physical interpretation. The aim of this paper is to explain these summer $Z_{50}$ and $D_{z}$ diurnal variations using model

Correspondence to: W. Kofman

(wlodek.kofman@planeto.obs.ujf-grenoble.fr) calculations of ion composition in the F-region, along with EISCAT observations for summer sunlit ionosphere.

\section{Observations}

The summer geomagnetically quiet period of $02 / 03$ July 1990 , with $A p=6 / 7$ and $F_{10.7}=276.6 / 253.8$, was chosen for our analysis. The electric fields observed with EISCAT were small $(2-5 \mathrm{mV} / \mathrm{m})$ during the whole period in question. Observed $\mathrm{NmF} 2$ and $h m \mathrm{~F} 2$ variations are shown in Fig. 1. F2-layer maximum electron concentration diurnal variation is observed to be rather small, with $\mathrm{NmF} 2$ maximizing soon after midnight (02 UT), while maximum $h m \mathrm{~F} 2$ are observed around midnight. This is the so-called effect of diurnal anomaly related to the direct solar photo-ionization of the F2-region during nighttime hours and large $h m \mathrm{~F} 2$ (Fig. 1, bottom) which results from the equatorward thermospheric wind during this part of the day. Decreased recombination efficiency due to large $h m \mathrm{~F} 2$, along with direct (although small) photo-ionization of the F2-region, result in nighttime $\mathrm{NmF} 2$ values larger than the daytime ones.

The EISCAT CP-1 program provides range profiles of $N_{e}$, $T_{e}, T_{i}$ and $V_{i}$ every $5 \mathrm{~min}$, with the antenna beam directed along the local geomagnetic field line. They were used to calculate median profiles over 1.5-2 hours of observations (17-25 values at each height) for the chosen periods. These median vertical profiles were then smoothed by a polynomial (up to the 5th degree) fitting before being used in calculations.

\section{Model calculations}

The sunlit auroral ionospheric F-region above the EISCAT facility in geomagnetically quiet conditions when electric fields are small is controlled by local processes typical for the midlatitude ionosphere (Farmer et al., 1984; Lathuillère and Brekke, 1985). Therefore, a model which takes into account the photo-ionization of neutral atmospheric species by 

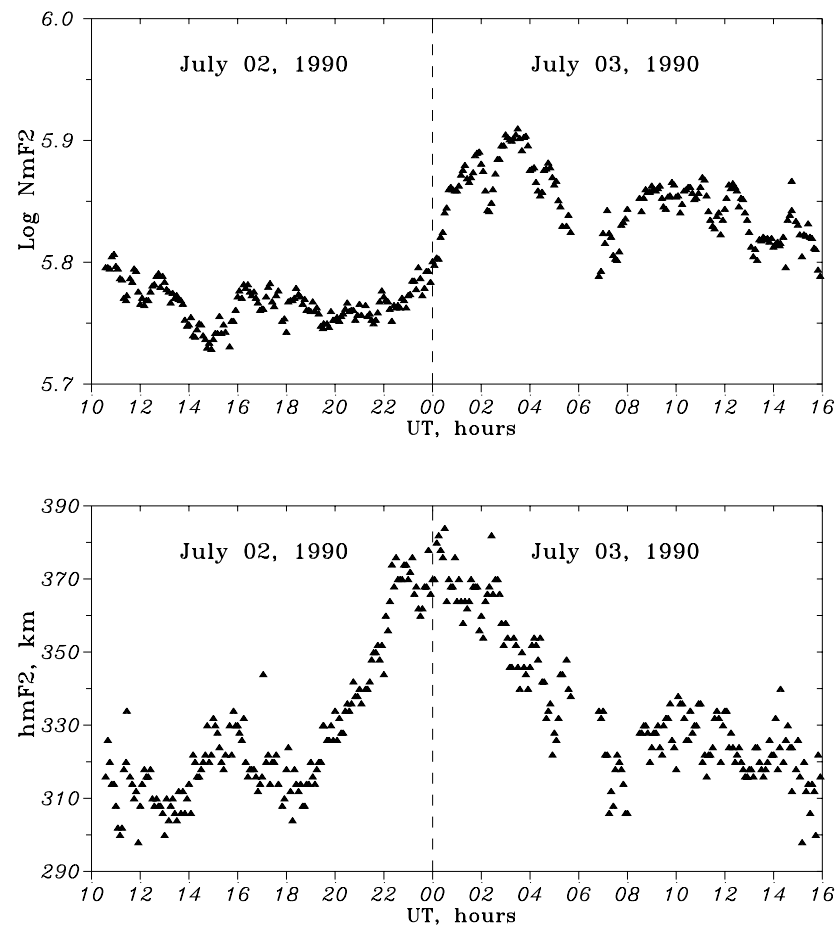

Fig. 1. Observed with EISCAT diurnal variations of $\mathrm{NmF} 2$ and hmF2 on 02/03 July 1990.

solar EUV, a set of main chemical processes, vertical plasma transport due to diffusion, thermospheric winds and electric fields may be used for such an analysis. The model used earlier for EISCAT and Millstone Hill incoherent scatter (IS) data analysis (Mikhailov and Foster, 1997; Mikhailov and Förster, 1997; Mikhailov and Schlegel, 1997, 1998) includes: transport process for $\mathrm{O}^{+}\left({ }^{4} \mathrm{~S}\right)$ and photo-chemical processes only for $\mathrm{O}^{+}\left({ }^{2} \mathrm{D}\right), \mathrm{O}^{+}\left({ }^{2} \mathrm{P}\right), \mathrm{O}_{2}^{+}\left(\mathrm{X}^{2} \Pi\right), \mathrm{N}^{+}, \mathrm{N}_{2}^{+}$and $\mathrm{NO}^{+}$ions in the $120-620 \mathrm{~km}$ height range. A two-component model of the solar EUV from Nusinov (1992) is used to calculate the photo-ionization rates in 35-wavelength intervals (100$1050 \AA$ A). The photo-ionization and photo-absorption crosssections are obtained from Torr et al. (1979) and Richards and Torr (1988). The only difference from the previous version of the model is in the $\mathrm{O}^{+}+\mathrm{N}_{2}$ reaction rate constant. Recent flowing afterglow laboratory measurements by Hierl et al. (1997) are included in the model. These measurements were made at $T_{n}=T_{i}=T_{v}$ (where $T_{n}$ is neutral, $T_{i}$ is ion temperature and $T_{v}$ is vibrational temperature of the excited $\mathrm{N}_{2}$ ) in a wide temperature range and take into account the effects of vibrationally excited $\mathrm{N}_{2}^{*}$. This may be important for summer high solar activity conditions (e.g. Pavlov, 1986; Ennis et al., 1995; Pavlov and Buonsanto, 1997; Pavlov et al., 1999, and references therein) considered in the present study. A comparison of different $\mathrm{O}^{+}+\mathrm{N}_{2}$ reaction rate constants using EISCAT observations has shown that the Hierl et al. (1997) rate coefficient for this reaction may be recommended for aeronomic calculations (Mikhailov and Schlegel, 2000).
Table 1. Dependence of calculations on the upper boundary height specification for daytime conditions (13 UT). Vertical plasma drift $W$ is given at $300 \mathrm{~km}$. Factors for neutral concentrations are given with respect to MSIS-83 model values with $T_{\mathrm{ex}}, S$ and $T_{120}$ shown in the table.

\begin{tabular}{llllll}
\hline $\begin{array}{l}\text { Height of } \\
\text { the upper } \\
\text { boundary, km }\end{array}$ & 400 & 450 & 500 & 550 & 600 \\
\hline$T_{e x}, \mathrm{~K}$ & 1480 & 1475 & 1489 & 1479 & 1455 \\
$S, \mathrm{~km}^{-1}$ & 0.0158 & 0.0159 & 0.0157 & 0.0156 & 0.157 \\
$T_{120}, \mathrm{~K}$ & 389 & 390 & 383 & 383 & 386 \\
$\mathrm{Fac}[\mathrm{O}]$ & 0.98 & 0.98 & 0.97 & 0.96 & 0.96 \\
$\mathrm{Fac}\left[\mathrm{O}_{2}\right]$ & 0.93 & 0.99 & 0.98 & 0.96 & 0.99 \\
$\mathrm{Fac}\left[\mathrm{N}_{2}\right]$ & 1.00 & 1.01 & 0.98 & 0.98 & 0.98 \\
$W, \mathrm{~m} \mathrm{~s}^{-1}$ & -9.0 & -9.2 & -8.4 & -7.9 & -7.6 \\
\hline
\end{tabular}

Vertical plasma drift $W$ used in the continuity equation for $\mathrm{O}^{+}$ions is obtained from the observed parameters as a difference between measured total vertical plasma velocity and diffusion velocity for $\mathrm{O}^{+}$ions. This is a standard approach usually used to find meridional thermospheric winds from IS observations (e. g., Buonsanto and Wittasse, 1999 and references therein). The expression (19.59) from Banks and Kockarts (1973) is used for $W$ specification

$$
\begin{aligned}
W=V_{z} & +\frac{k}{m_{i} \sum v_{i j}} \sin ^{2} I\left\{T_{i} \frac{\ln N_{i}}{d h}+T_{e} \frac{d \ln N_{e}}{d h}+\frac{g m_{i}}{k}\right. \\
& \left.+\frac{d\left(T_{e}+T_{i}\right)}{d h}\right\}
\end{aligned}
$$

where $V_{z}=V_{i} \sin I, v_{i j}$ are diffusion collision frequencies for $\mathrm{O}^{+}$related to momentum transfer collision frequencies $v^{*}$ by the expression (see Eq. 19.13 in Banks and Kockarts, 1973) $v_{i j}=m_{j} /\left(m_{i}+m_{j}\right) v_{i j}^{*}$, where $i$ applies to $\mathrm{O}^{+}$ions and $j$ applies to other neutral or ionized gas species; all other symbols are standard. Collisions of $\mathrm{O}^{+}$ions with neutral $\mathrm{O}, \mathrm{O}_{2}, \mathrm{~N}_{2}$ and $\mathrm{NO}^{+}, \mathrm{O}_{2}^{+}, \mathrm{N}_{2}^{+}, \mathrm{N}^{+}$ions were taken into account. All $\mathrm{O}^{+}$ion collision frequencies were taken from Banks and Kockarts (1973). Ion concentrations used in Eq. (1) are known at each iteration of fitting calculated $\mathrm{Ne}(h)$ to the experimental one. Calculations are made with the upper boundary conditions specified at different heights in the 400-600 km height range. Normally the results are rather insensitive to the choice of the upper boundary height (see Table 1) and any calculation can be used as a solution. But the scatter of the measured $V_{i}$ may increase with height (as observations show) and the reliability of the calculated median $V_{i}$ decreases at high altitudes for such cases. This may result in some dependence of the solutions on the upper boundary height choice. Therefore, we usually specify the upper boundary at $500 \mathrm{~km}$.

Observed (median and smoothed) $T_{e}(h)$ and $T_{i}(h)$ profiles are used in the calculations. No correction was ap- 
Table 2. Calculated thermospheric parameters in comparison with MSIS-83 values (second line). Concentrations and meridional winds are given at $300 \mathrm{~km}$.

\begin{tabular}{lcclllll}
\hline Periods & $T_{\mathrm{ex}}, \mathrm{K}$ & $T_{120}, \mathrm{~K}$ & $S, \mathrm{~km}^{-1}$ & $\log [\mathrm{O}]$ & $\log \left[\mathrm{O}_{2}\right]$ & $\log \left[\mathrm{N}_{2}\right]$ & $V_{n x}, \mathrm{~m} \mathrm{~s}^{-1}$ \\
\hline 03 July 90 & 1411 & 407 & 0.019 & 8.615 & 7.326 & 8.614 & +108.0 \\
02 UT & 1406 & 403 & 0.018 & 8.627 & 7.186 & 8.621 & \\
\hline 03 July 90 & 1419 & 415 & 0.018 & 8.707 & 7.304 & 8.669 & +32.3 \\
04 UT & 1422 & 415 & 0.017 & 8.669 & 7.216 & 8.627 & \\
\hline 03 July 90 & 1480 & 422 & 0.017 & 8.768 & 7.338 & 8.744 & -19.3 \\
07 UT & 1458 & 425 & 0.017 & 8.769 & 7.292 & 8.690 & \\
\hline 03 July 90 & 1500 & 415 & 0.016 & 8.835 & 7.250 & 8.734 & -8.7 \\
10 UT & 1508 & 412 & 0.017 & 8.810 & 7.304 & 8.730 & \\
\hline 02 July 90 & 1489 & 383 & 0.016 & 8.714 & 7.136 & 8.595 & -38.0 \\
13 UT & 1521 & 398 & 0.016 & 8.774 & 7.231 & 8.682 & \\
\hline 02 July 90 & 1517 & 414 & 0.014 & 8.767 & 7.152 & 8.667 & -15.6 \\
16 UT & 1556 & 410 & 0.015 & 8.728 & 7.239 & 8.667 & \\
\hline 02 July 90 & 1507 & 400 & 0.015 & 8.645 & 7.249 & 8.571 & +47.3 \\
19 UT & 1524 & 418 & 0.016 & 8.707 & 7.273 & 8.698 & \\
\hline 02 July 90 & 1457 & 393 & 0.016 & 8.539 & 7.230 & 8.528 & +145.7 \\
21 UT & 1454 & 410 & 0.017 & 8.682 & 7.248 & 8.692 & \\
\hline
\end{tabular}

plied to these profiles, as the calculated $\mathrm{O}^{+} / \mathrm{Ne}$ ratio usually is close to the standard EISCAT model for quiet time conditions (Fig. 4). Such a correction makes sense only for storm conditions when deviations from the model are essential (Mikhailov and Schlegel, 1997, 1998; Mikhailov and Foster, 1997; Mikhailov and Förster, 1999). In our case, the maximal deviation from the standard model is about $15 \%$ at $200 \mathrm{~km}$ (Fig. 4). This should result in a 15\% correction for $T_{i}$ and $13 \%$ for $T_{e}$ at the $200 \mathrm{~km}$ height (Waldteufel, 1971) and this is not very important for the calculated aeronomic parameters, as our previous analysis has shown.

Using standard multi-regressional methods, we fit the calculated $N_{e}(h)$ profile to the observed one and find by this method: $T_{\mathrm{ex}}$, shape parameter $S$ for the $T_{n}(h)$ profile, $T_{120}$ and factors for the MSIS-83 [O], $\left[\mathrm{O}_{2}\right],\left[\mathrm{N}_{2}\right]$ concentrations, as well as for the total EUV flux from the Nusinov (1992) model. The method by Mikhailov and Schlegel (1997, 2000 ) is still under development and various versions of this method exist. In one of them used in present study, exospheric temperature $T_{\mathrm{ex}}$ is included to the list of unknown parameters. This way of searching for $T_{\mathrm{ex}}$ is different from the earlier approach used in Mikhailov and Schlegel (1997), Mikhailov and Foster (1997), Mikhailov and Förster, (1997), and it turned out to be more straightforward and efficient, as well as more general, as it uses the most reliable parameter, $N_{e}(h)$ observed with the IS method, while $T_{e}(h)$ and $T_{i}(h)$ profiles depend on the ion composition model applied during the incoherent scatter data analysis (e.g. Lathuillère et al., 1983; Alcaydé et al., 1996). There is also a problem with the specification of the frictional term in the equation of ion energy conservation when electric fields are strong enough. Moreover, for strong convection electric fields, the ion velocity distribution is no longer Maxwellian (St.-Maurice and Schunk, 1979; Hubert and Kinzelin, 1992) and this basic assumption in the data analysis is not valid. There are also doubts if the energy conservation equation for $\mathrm{O}^{+}$ions in the F2-region normally used to find $T_{n}$ takes into account all necessary processes (Oliver, 1997).

Although we are not dealing with the heights below $150 \mathrm{~km}$, it was found that the method works better if one included the MSIS $T_{120}$ value; thus, $T_{120}$ was formally added to the list of searched parameters. But it should be stressed that this is just a technical step and the extension of $T_{n}$, [O], $\left[\mathrm{O}_{2}\right],\left[\mathrm{N}_{2}\right]$ down to $120 \mathrm{~km}$ height is just an extrapolation, as we do not fit any $N_{e}(h)$ profile below $160 \mathrm{~km}$ height.

The stationary form of the continuity equations is used in our method and daytime sunlit ionosphere is assumed. Therefore, in principle, only periods of relative stability in $\mathrm{NmF} 2$ and $h m \mathrm{~F} 2$ variations around noon hours may be used for the analysis. But the analyzed period of 02/03 July 1990 shows very small $\mathrm{NmF} 2$ variations for most of the day (Fig. 1); therefore, the method was applied to more than just 
July 03, 1990 (02 UT)
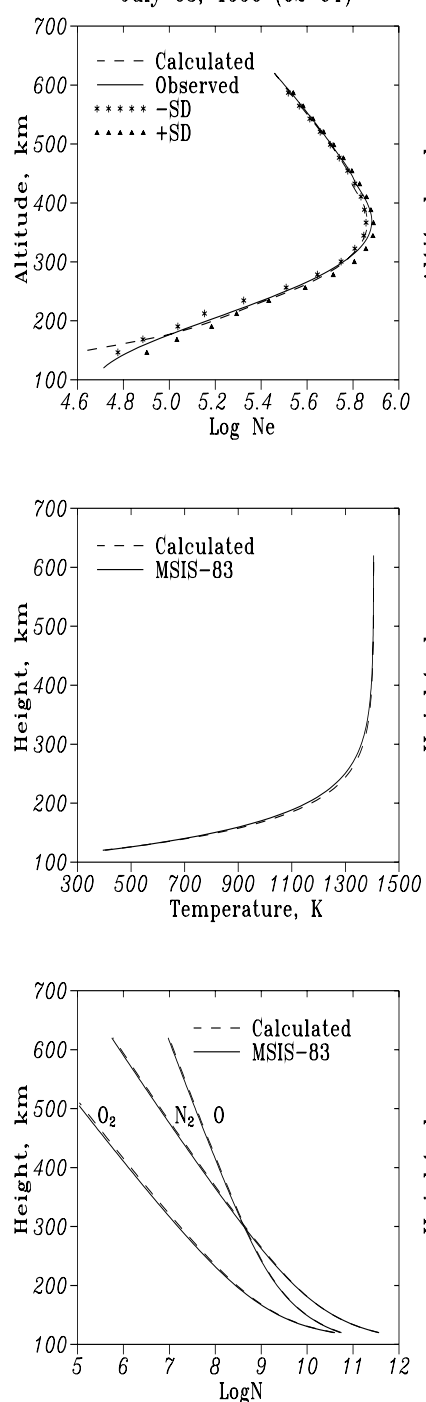
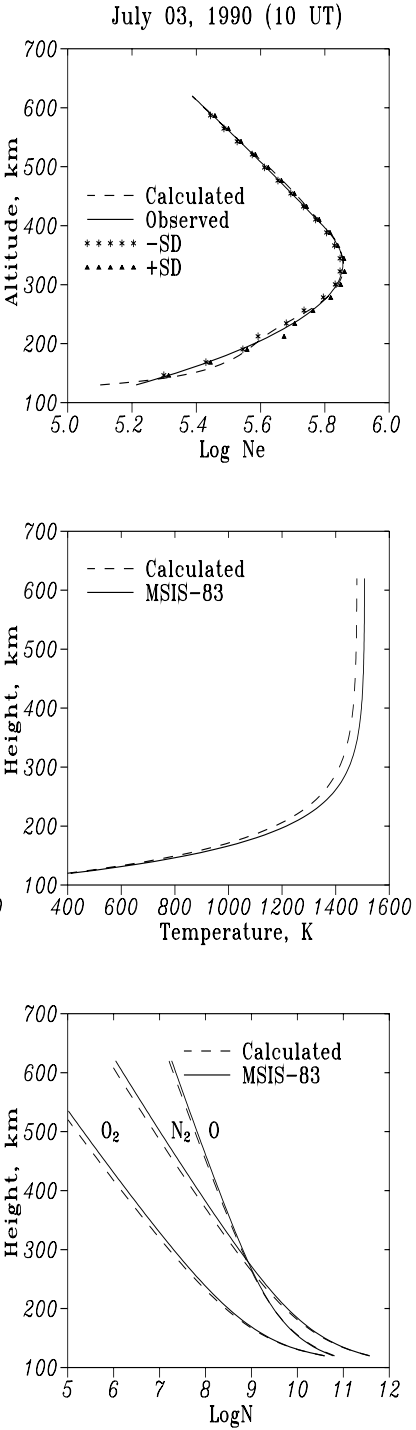

Fig. 2. Observed (together with a band of standard deviations) and calculated $N_{e}(h)$ profiles for two UT moments (top panel). Calculated along with MSIS- $83 T_{n}, \mathrm{O}, \mathrm{O}_{2}$, and $\mathrm{N}_{2}$ height profiles (middle and bottom panels).

the hours around noon and acceptable results were obtained (see Table 2). Only the hours around midnight, when the solar zenith angle was close to $90^{\circ}$, could not be developed properly. Two examples of $N_{e}(h)$ fitting and the calculated $T_{n}(h),[\mathrm{O}],\left[\mathrm{O}_{2}\right]$, and $\left[\mathrm{N}_{2}\right]$ height profiles, along with the MSIS-83 thermospheric model, are shown in Fig. 2.

Dependence of the calculations on the height of the upper boundary condition specification (where observed $\mathrm{Ne}$ values are used) is shown in Table 1 for daytime (13 UT) conditions $(\mathrm{LT}=\mathrm{UT}+1.3)$. In general, the effect of the upper boundary height change is seen as small, but the large heights of the upper boundary (550 and $600 \mathrm{~km}$ ) give $W$ at $300 \mathrm{~km}$, which differ from the other values. We suppose that this is the effect of decreasing the vertical velocity determination accuracy at high altitudes.

The analyzed periods and calculated thermospheric pa-
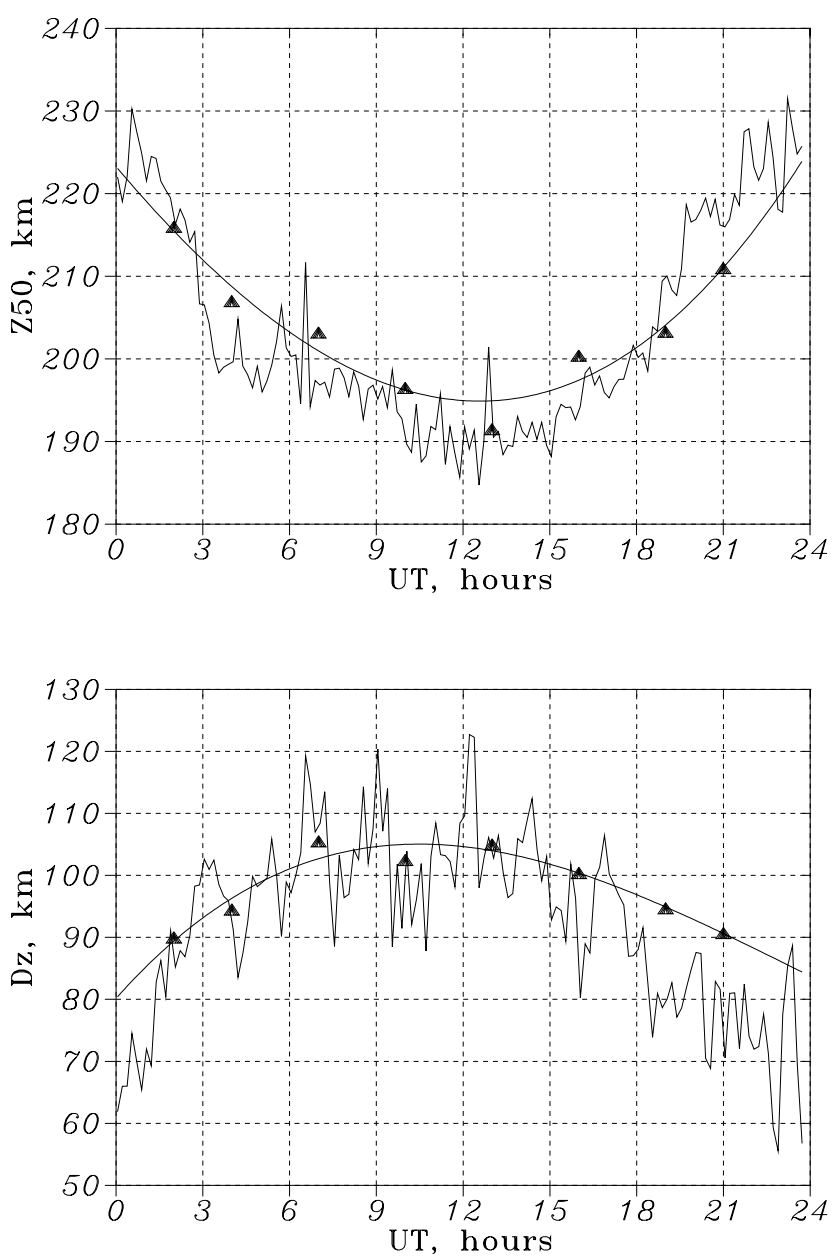

Fig. 3. Calculated (triangles) and experimental from Litvine et al. (1998) $Z_{50}$ and $D_{z}$ diurnal variations. A smooth curve is the least squares approximation of the calculated (triangles) values.

rameters, in comparison with the MSIS- 83 model predictions, are given in Table 2. The calculated thermospheric parameters for this quiet day are seen to be close to the MSIS83 model values (see also Fig. 2). Average absolute differences are: less than $1 \%$ for $T_{\mathrm{ex}}, 1.8 \%$ for $T_{120}, 12 \%$ for [O], $18 \%$ for $\left[\mathrm{O}_{2}\right]$ and $16.5 \%$ for $\left[\mathrm{N}_{2}\right]$. This is a normal result for quiet time periods provided by this method (e.g. Mikhailov and Schlegel, 1997; Mikhailov and Förster, 1999). The largest deviations from the MSIS- 83 take place in the evening (21 UT) when the F2-layer obviously was non-stationary; abrupt changes of $h m \mathrm{~F} 2$ are seen during these periods (Fig. 1). The calculated from $W$ meridional thermospheric wind, $V_{n x}$ shows usual diurnal variation being strong equatorward during nighttime and poleward during daytime hours (e.g. Lathuillère and Lilensten, 1997; Buonsanto and Witasse, 1999 and references therein).

The calculated $Z_{50}$ and $D_{z}$ diurnal variations; along with the Litvine et al. (1998) experimental values for summer high solar activity, are given in Fig. 3. Our calculations demonstrate the anti-correlation between $Z_{50}$ and $D_{z}$ variations, in accordance with the empirical model by Litvine et al. (1998). 


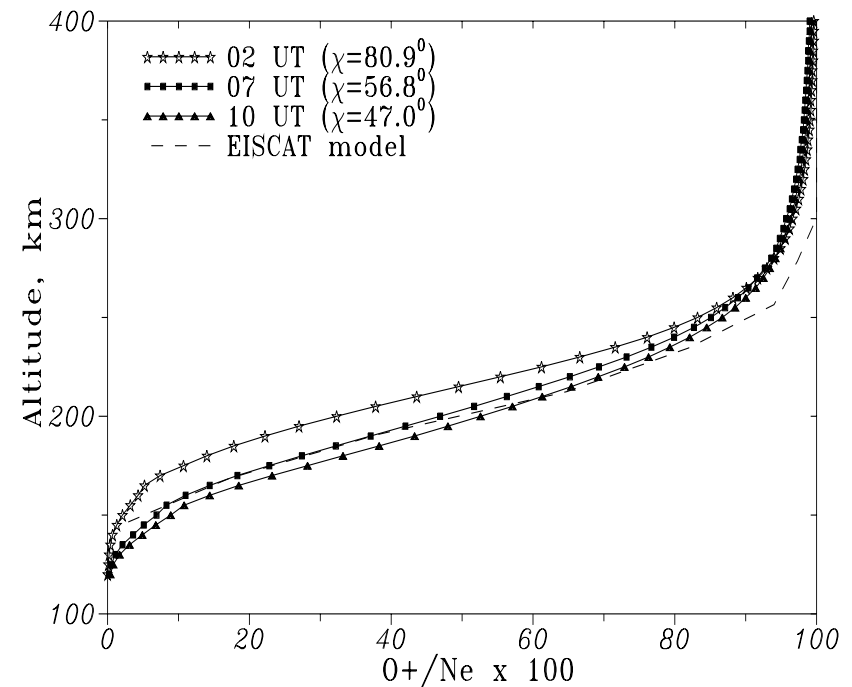

Fig. 4. Calculated height profiles of the $\mathrm{O}^{+} / \mathrm{Ne}$ ratio at three solar zenith angles. The standard EISCAT ion composition model is shown for a comparison (dashes).

The transition level between atomic and molecular ions is the lowest $(191 \mathrm{~km})$ during daytime hours (13 UT) and the highest $(216 \mathrm{~km})$ during nighttime. The width of the $10-90 \%$ layer varies in an opposite way, maximizing $(105 \mathrm{~km})$ during daytime hours and minimizing $(90 \mathrm{~km})$ in the nighttime. On the other hand, the experimental values from Litvine et al. (1998) are seen to be shifted a little with respect to the calculated curves. This may be explained by the chosen period for our analysis (see later). Let us analyze the physical reasons for such diurnal variations of $Z_{50}$ and $D_{2}$.

\section{Interpretation}

Calculated height profiles of the $\mathrm{O}^{+} / \mathrm{Ne}$ ratio are shown in Fig. 4 for three solar zenith angles $\chi$ corresponding to 02,07 and $10 \mathrm{UT}$. This ratio demonstrates systematic changes with the solar zenith angle. Any level of constant $\mathrm{O}^{+} / \mathrm{Ne}$ ratio in the $10-90 \%$ range descends with the decreasing of the solar zenith angle. Figure 5 shows these variations for the three levels $(10,50$, and $90 \%)$ discussed in the paper. The height variation of the $10 \%$ level is larger (about $35 \mathrm{~km}$ ) compared to the $90 \%$ level variation (about $15 \mathrm{~km}$ ). Therefore, the decrease in $D_{z}$ is mainly due to the uplifts of the $10 \%$ level when we pass from daytime to nighttime hours. These results obtained from our calculations also follow from an analysis of a scheme of photochemical processes in the daytime ionosphere. For the analyzed period of very high solar activity and daytime hours, the photochemical equilibrium is valid for the main ions up to $200 \mathrm{~km}$ and even higher. For instance, the estimated characteristic times for $\mathrm{O}^{+}$ions, with respect to recombination $1 / \beta=1.5 \cdot 10^{2} \mathrm{~s}$ to diffusion $H^{2} / D$, is about $1.0 \cdot 10^{5} \mathrm{~s}$, and to vertical transport $H / W$, is about $2.0 \cdot 10^{4} \mathrm{~s}$ at $200 \mathrm{~km}$. A comparison of $N_{e}(h)$ profiles calcu-

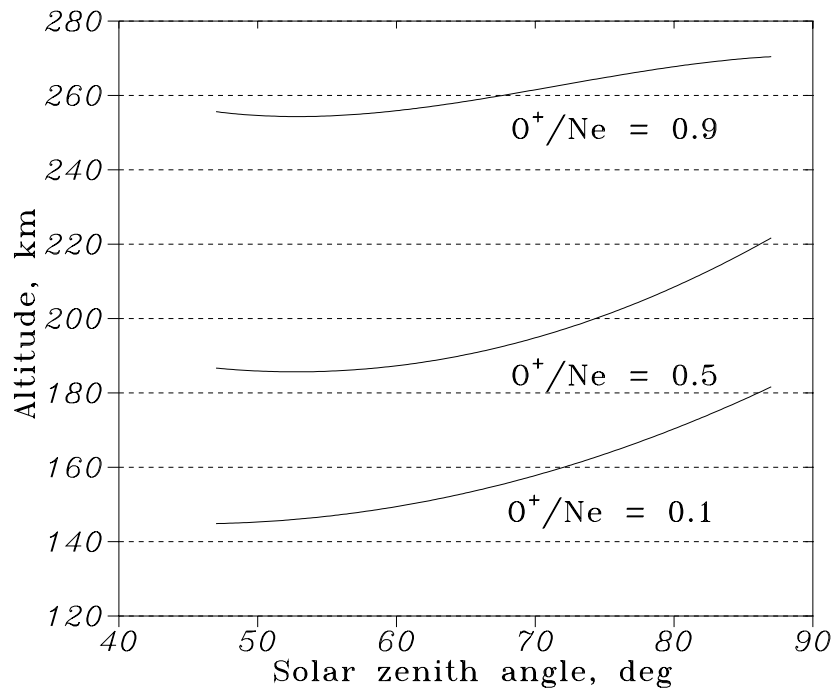

Fig. 5. Calculated variations of the $\mathrm{O}^{+} / \mathrm{Ne}$ ratio at three levels $(10$, 50 and $90 \%$ ) with solar zenith angle. Note the steepness of the variation is decreased at high altitudes ( $90 \%$ level).

lated with a complete set of processes and in a photochemical equilibrium is shown in Fig. 6 for daytime (13 UT) conditions. The observed $N_{e}(h)$ profile is shown as well in order to demonstrate the quality of model $N_{e}(h)$ fitting. Photochemical equilibrium is valid up to $200 \mathrm{~km}$. In accordance with the mechanism of the F2-layer formation, additional plasma is transfered from the topside to the area just below the F2 maximum, where electron density turns out to be a little higher than what photochemical equilibrium provides. Therefore, a qualitative analysis of the ion composition variations can be done in the framework of the photochemical equilibrium.

If one leaves out only the main processes which control the ionosphere formation in the $140-220 \mathrm{~km}$ height range, then ion concentrations may be written as follows (e.g IvanovKholodny and Nikoljsky, 1969):

$$
\begin{aligned}
& {\left[\mathrm{O}^{+}\right]=\frac{q\left(\mathrm{O}^{+}\right)}{\gamma_{1}\left[\mathrm{~N}_{2}\right]+\gamma_{2}\left[\mathrm{O}_{2}\right]}} \\
& {\left[\mathrm{N}_{2}^{+}\right]=\frac{q\left(\mathrm{~N}_{2+}\right)}{\gamma_{3}[\mathrm{O}]}} \\
& {\left[\mathrm{O}_{2^{+}}\right]=\frac{q\left(\mathrm{O}_{2}^{+}\right)+\gamma_{2}\left[\mathrm{O}_{2}\right]\left[\mathrm{O}^{+}\right]}{\alpha_{2} n_{e}}} \\
& {\left[\mathrm{NO}^{+}\right]=\frac{\gamma_{1}\left[\mathrm{~N}_{2}\right]\left[\mathrm{O}^{+}\right]+\gamma_{3}[\mathrm{O}]\left[\mathrm{N}_{2}^{+}\right]}{\alpha_{1} n_{e}}} \\
& n_{e}=\left[\mathrm{O}^{+}\right]+\left[\mathrm{O}_{2}^{+}\right]+\left[\mathrm{NO}^{+}\right]
\end{aligned}
$$

Equilibrium concentration of $\mathrm{N}_{2}^{+}$ions is negligible compared to the main ions (e.g. Goldberg and Blumle, 1970). From these expressions, a quadratic equation may be written for the $\mathrm{O}^{+} / n_{e}$ ratio

$$
\left(\frac{n_{e}}{\mathrm{O}^{+}}\right)^{2}-\frac{n_{e}}{\mathrm{O}^{+}}-A=0,
$$




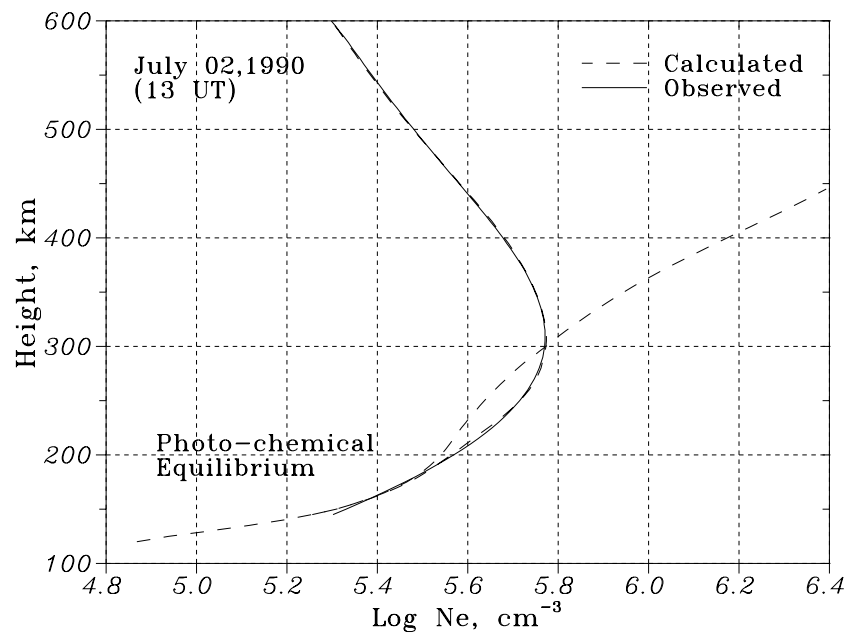

Fig. 6. Calculated $N_{e}(h)$ profiles with a complete set of processes and in a photo-chemical equilibrium for daytime conditions. The observed profile is shown as well.

where

$$
\begin{aligned}
A=\frac{\beta^{2}}{q\left(\mathrm{O}^{+}\right)^{2}}\left[\frac{q\left(\mathrm{O}_{2}^{+}\right)}{\alpha_{2}}+\frac{q\left(\mathrm{~N}_{2}^{+}\right)}{\alpha_{1}}\right] \\
+\frac{\beta}{q\left(\mathrm{O}^{+}\right)}\left[\frac{\gamma_{2}\left[\mathrm{O}_{2}\right]}{\alpha_{2}}+\frac{\gamma_{1}\left[\mathrm{~N}_{2}\right]}{\alpha_{1}}\right]
\end{aligned}
$$

and $\beta=\gamma_{1}\left[\mathrm{~N}_{2}\right]+\gamma_{2}\left[\mathrm{O}_{2}\right]$

A positive solution of (2) for $\mathrm{O}^{+} / n_{e}$ is

$\frac{\left[\mathrm{O}^{+}\right]}{n_{e}}=\left(\frac{1}{2}+\sqrt{\frac{1}{4}+A}\right)^{-1}$

The case of $A \ll 1 / 4$ corresponds to large heights, where $\left[\mathrm{O}^{+}\right] / n_{e} \approx 1$. The other case of $A \gg 1 / 4$ corresponds to lower heights, where $\left[\mathrm{O}^{+}\right] / n_{e} \ll 1$ and molecular ions dominate.

Height variations of the two terms in Eq. (3), in comparison with 1/4, are given in Fig. 7 for the daytime hours of 02 July 1990. The condition $A \gg 1 / 4$ is valid up to $200 \mathrm{~km}$ height. The other result is that the two terms in Eq. (3) show similar height variations which are close to the height variation of $A$, at least up to $250 \mathrm{~km}$; therefore, any of the terms in Eq. (3) can be used for further analysis.

Let us analyze the solution (4) with respect to the $\left[\mathrm{O}^{+}\right] / n_{e}$ dependence on the solar zenith angle and height. For the sake of simplicity, we may assume that the isothermal neutral atmosphere consists of atomic oxygen and molecules, $M$ $\left(\mathrm{O}_{2}\right.$ and $\left.\mathrm{N}_{2}\right)$, distributed in accordance with the barometric law: $[\mathrm{O}]=[\mathrm{O}]_{0} \exp (-z / H)$ and $[M]=[M]_{0} \exp (-2 z / H)$, where $H=k T_{n} / m g$ is the atomic oxygen scale height. The photoionization rates may be written as $q\left(\mathrm{O}^{+}\right)=$ $j_{0}[\mathrm{O}] \exp (-a \mathrm{Ch} \chi)$ and $q\left(M^{+}\right)=j_{M}[M] \exp (-a \mathrm{Ch} \chi)$, where $j$ is the ionization efficiency depending on the incident solar EUV flux and ionization cross-sections, $\mathrm{Ch} \chi$ is

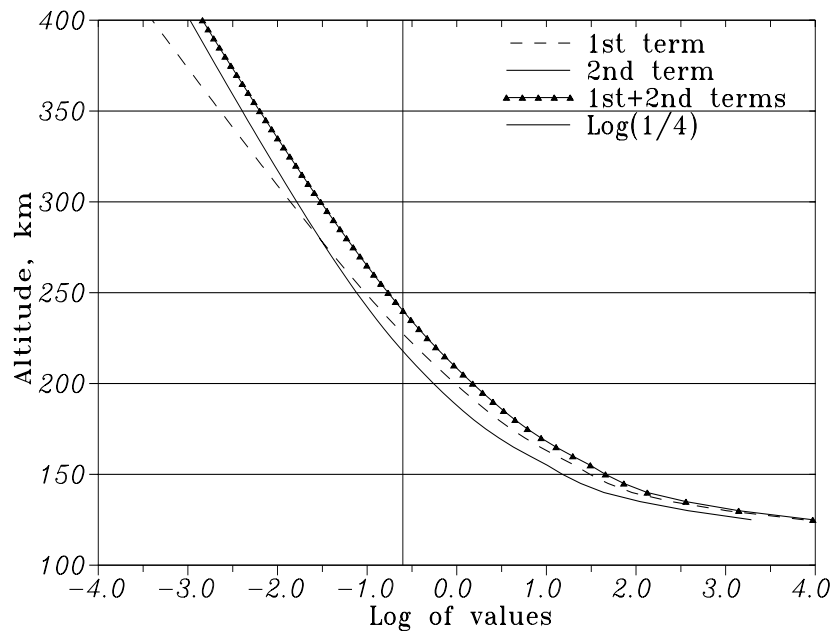

Fig. 7. Comparison of the two terms from the expression (3). Vertical line corresponding to $\log _{10}(1 / 4)($ see $(4))$ divides the ionosphere by the lower and the upper parts where molecular and atomic ions dominate.

the Chapman function for the solar zenith angle $\chi$, and $a$ includes the column density of neutrals multiplied by absorption cross-sections, with $a$ being the same for the atomic and molecular species. The linear loss coefficient $\beta$ may be written as $\beta=\gamma[M]$. In this case, it may be shown that

$A \cong\left[C_{1} \exp \left(\frac{-4 z}{H}\right)+C_{2} \exp \left(\frac{-3 z}{H}\right)\right] \exp (a \operatorname{Ch} \chi)$

where $C_{1}$ and $C_{2}$ are coefficients which are independent on height, $z$ and the solar zenith angle, $\chi$. As described above, any term in the expression for $A$ can be used for the analysis below $200 \mathrm{~km}$, as both demonstrate height variations similar to the height variation of $A$ (see Fig. 7). Therefore, let us analyze the first term in Eq. (5). For lower altitude case $(A>$ $1 / 4)$, we obtain from Eqs. (4) and (5):

$\left[\mathrm{O}^{+}\right] / n_{e} \approx C \exp \left(\frac{2 z}{H}\right) \exp \left(-\frac{1}{2} a \mathrm{Ch} \chi\right)$

where $C=1 / \sqrt{C_{1}}$ is a coefficient independent on $z$ and $\chi$. Therefore, in the height range where $A>1 / 4$, the $\left[\mathrm{O}^{+}\right] / n_{e}$ ratio increases with height at any solar zenith angle and decreases with solar zenith angle at any height. The steepness of the $\left[\mathrm{O}^{+}\right] / n_{e}$ dependence on $\mathrm{Ch} \chi$ should decrease as we move to higher altitudes, where $A$ becomes $<1 / 4$. Using Eq. (6), it is possible to write an explicit expression for the height $z$ of a given $R=\left[\mathrm{O}^{+}\right] / n_{e}$ ratio

$z=\frac{H}{2} \ln (R / C)+\frac{H a}{4} \mathrm{Ch} \chi$

Using these analytical expressions, it is possible to interpret the results of our calculations obtained with an ionospheric model, which takes into account the whole set of processes. 


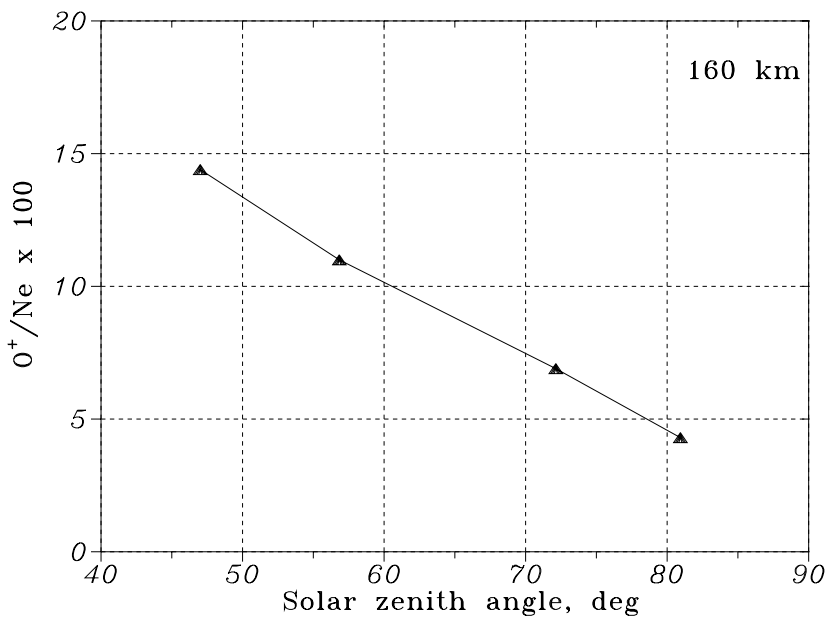

Fig. 8. Calculated dependence of the $\mathrm{O}^{+} / \mathrm{Ne}$ ratio on the solar zenith angle at a fixed $(160 \mathrm{~km})$ height.

\section{The dependence of $Z_{50}$ on solar zenith angle}

The $\left[\mathrm{O}^{+}\right] / n_{e}$ ratio always increases with height at any solar zenith angle (Fig. 4), as it follows from Eq. (6). This is due to different laws of plasma recombination: a quadratic one at lower heights, where molecular ions dominate, and a linear one at high altitudes, where atomic oxygen ions dominate. On the other hand, the $\left[\mathrm{O}^{+}\right] / n_{e}$ ratio decreases at a given height with solar zenith angle (Fig. 8), as it follows also from Eq. (6). Therefore, we have to shift to higher altitudes to keep a given $\left[\mathrm{O}^{+}\right] / n_{e}$ ratio when the solar zenith angle increases. This dependence is clearly seen from Eq. (7) as well. This explains the observed diurnal variation of the $Z_{50}$ parameter. From a physical point of view, the increase of the $Z_{50}$ height during the night hours is just due to the shift of the ionization production maximum to higher altitudes, when $\mathrm{Ch} \chi$ increases. Figure 9 gives height profiles for the production rates of $\mathrm{O}^{+}, \mathrm{O}_{2}+, \mathrm{N}_{2}+$ ions, as well as the total production rate along with ion concentrations for the main ions for 13 and 19 UT. The effect of the sharp decrease in the rate of ion production, and a corresponding decrease in ion concentrations at lower heights is clearly seen. There is an overall shift of the experimental $Z_{50}$ values with respect to the calculations (Fig. 3, top). This may be explained by the choice of the 02/03 July 1990 period for our analysis. Summer conditions at high solar activity used by Litvine et al. (1998) are presented primarly in 1992 when the average $F_{10.7}$ was around 120 for summer months, while for the analyzed period, the three monthly mean $F_{10.7}$ was 190 and the daily $F_{10.7}$ was 276 . The higher neutral temperature on the day analyzed explains the shift between the experimental and calculated $Z_{50}$ values in Fig. 3. The experimental $Z_{50}$ values in Litvine et al. (1998, their Fig. 3, left hand, top) are also shifted to lower heights for low solar activity compared to solar maximum, and this may also be related to different neutral temperatures (see expression 7).
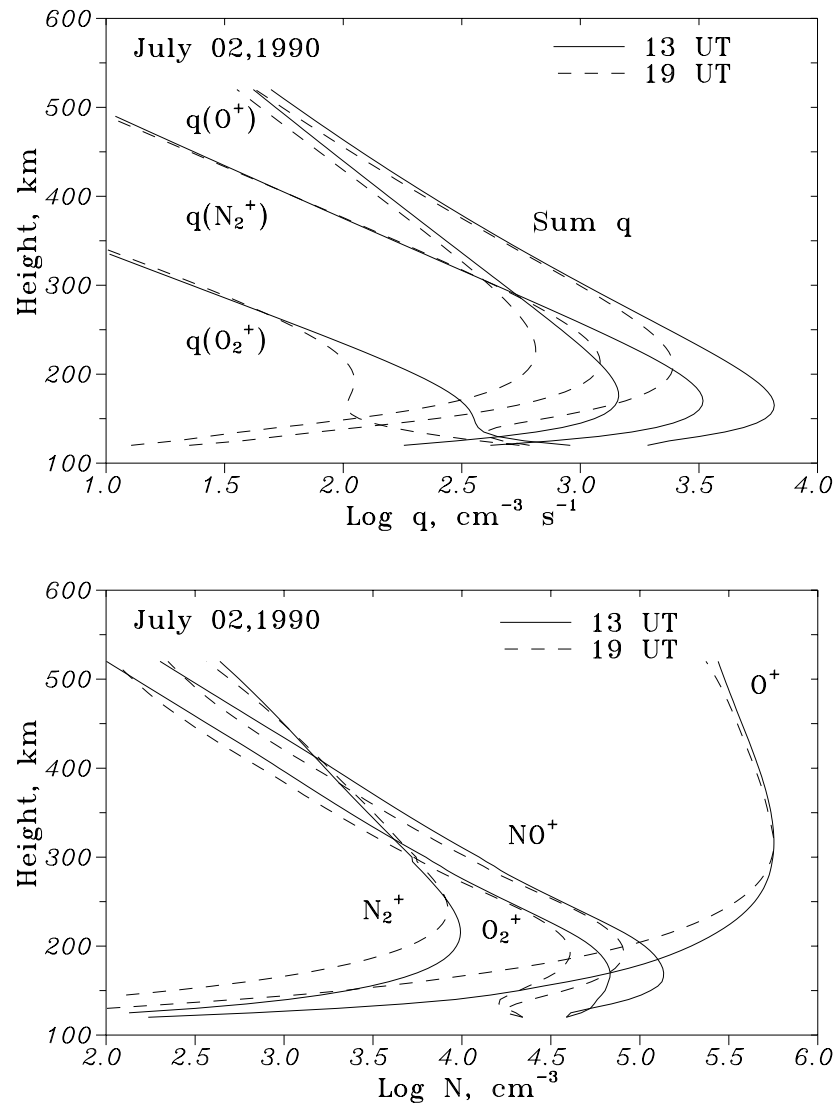

Fig. 9. Calculated height profiles of photo-ionization rates and corresponding ion concentrations for daytime (13 UT) and evening (19 UT) hours. Note the strong decrease in the photo-ionization rates at lower heights in the evening.

\section{The dependence of $D_{z}$ on solar zenith angle}

As it follows from the results of model calculations (Fig. 5), the steepness of the $\left[\mathrm{O}^{+}\right] / n_{e}$ dependence on the solar zenith angle is different at high and low altitudes. This follows from Eq. (4) when $A$ becomes $<1 / 4$ (high altitudes) and no dependence on the solar zenith angle for the $\left[\mathrm{O}^{+}\right] / n_{e}$ ratio is expected. Therefore, the observed decrease of $D_{z}$ (Fig. 3) is mainly due to the uplift of the $10 \%$ level when we pass to large solar zenith angles in the evening. Again, this is due to the variations of ionization production function for large solar zenith angles (Fig. 9). The calculated $D_{z}$ values are seen to be larger than the experimental ones during nighttime hours (Fig. 3, bottom). This may be due to the chosen period (02/03 July) for our analysis, when the F2-layer, in fact, was sunlit during the nighttime hours, while the average experimental values include nighttime conditions with $\chi>90^{\circ}$. Direct photo-ionization, as it takes place on 02/03 July, produces sufficient ion concentrations at the $10 \% \mathrm{O}^{+} / \mathrm{Ne}$ level, broadening the F2-layer and increasing $D_{z}$. 


\section{Conclusions}

The anticorrelation between $Z_{50}$ and $D_{z}$ parameters in their diurnal variations, revealed for the first time by Litvine et al. (1998), may be explained using the present day understanding of the physical processes in the ionospheric F1 and lower F2-regions. Model calculations reproduce such diurnal variations of $Z_{50}$ and $D_{z}$ parameters, which are explained by different variations of ion composition at different ionospheric heights. The main reason for the observed $Z_{50}$ and $D_{z}$ variation is due to different ion composition (molecular at low and atomic at high altitudes), as well as to diurnal variations of the photo-ionization rates.

During low solar activity, variations of the $Z_{50}$ and $D_{z}$ parameters are practically the same as those at solar maximum (Litvine et al., 1998), but shifted a little bit to lower heights for the $Z_{50}$ parameter and with less amplitude for the $D_{z}$ variation. This may be explained by lower neutral temperatures during low solar activity.

Acknowledgements. The authors thank the Director and the staff of EISCAT for running the radar and providing the data. The EISCAT Scientific Association is funded by scientific agencies of Finland (SA), France (CNRS), Germany (MPG), Japan (NIPR), Norway (NF), Sweden (NFR), and the United Kingdom (PPARC).

Topical Editor M. Lester thanks P. L. Blelly and another referee for their help in evaluating this paper.

\section{References}

Alcaydé, D., Fontanari, J., Blelly, P.-L., and Lathuillère, C., On the influence of ion composition in the F1-region on incoherent scatter spectra, Ann. Geophysicae, 14, 1526-1529, 1996.

Banks, P. M. and Kockarts, G., Aeronomy, Academic Press, New York, London, 1973.

Buonsanto, M. J. and Witasse, O. G., An updated climatology of thermospheric neutral winds and $\mathrm{F}$ region ion drifts above Millstone Hill, J. Geophys. Res., 104, 24 675-24 687, 1999.

Ennis, A. E., Bailey, G. J., and Moffett, R. J., Vibrational nitrogen concentration in the ionosphere and its dependence on season and solar cycle, Ann. Geophysicae, 13, 1164- 1171, 1995.

Farmer, A. D., Lockwood, M., Horne, R. B., Bromage, B. J. I., and Freeman, K. S. C., Field-perpendicular and field-aligned plasma flows observed by EISCAT during a prolonged period of northward IMF, J. Atmos. Terr. Phys., 46, 473-488, 1984.

Goldberg, R. A. and Blumle, L. J., Positive composition from a rocket-borne mass spectrometre, J. Geophys. Res., 75, 133-142, 1970.

Hierl, P. M., Dotan, I., Seeley, J. V., Van Doran, J. M., Morris, R. A., and Viggiano, A. A., Rate coefficients for the reactions of $\mathrm{O}^{+}$with $\mathrm{N}_{2}$ and $\mathrm{O}_{2}$ as a function of temperature (300-1800 K), J. Chem. Phys., 106 (9), 3540-3544, 1997.

Hubert, D. and Kinzelin, E., Atomic and molecular ion temperatures and ion anisotropy in the auroral $\mathrm{F}$ region in the presence of large electric fields, J. Geophys. Res., 97, 1053-1059, 1992.

Ivanov-Kholodny, G. S. and Nikoljsky, G. M., The Sun and the Ionosphere, Nauka, M., p.258, 1969 (in Russian).

Lathuillère, C., Lejeune, G., and Kofman, W., Direct measurements of ion composition with EISCAT in the high-latitude F1 region, Radio Sci., 18, 887-893, 1983.
Lathuillère, C. and Brekke, A., Ion composition in the auroral ionosphere as observed by EISCAT, Ann. Geophysicae, 3, 557-568, 1985.

Lathuillère, C. and Pibaret, B., A statistial model of ion composition in the auroral lower F region, Adv. Space Res., 12, 147-156, 1992.

Lathuillère, C. and Lilensten, J., Meridional wind in the auroral thermosphere: Results from EISCAT and WINDII-O(1D) coordinated measurements, J. Geophys. Res., 102, 4487-4492, 1997.

Litvine, A., Kofman, W., and Cabrit, B., Ion composition measrements and modelling at altitudes from 140 to $350 \mathrm{~km}$ using EISCAT measurements, Ann. Geophysicae, 16, 1159-1168, 1998.

Mikhailov, A. V. and Foster, J. C., Daytime thermosphere above Millstone Hill during severe geomagnetic storm, J. Geophys. Res., 102, 17 275-17 282, 1997.

Mikhailov, A. V. and Förster, M., Day-to-day thermosphere parameter variation as deduced from Millstone Hill incoherent scatter radar observations during March 16-22, 1990 magnetic storm period, Ann. Geophysicae, 15, 1429-1438, 1997.

Mikhailov, A. V. and Förster, M., Some F2-layer effects during the January 06-11, 1997 CEDAR storm period as observed with the Millstone Hill incoherent scatter facility, J. Atmos. Solar-Terr. Phys, 61, 249-261, 1999.

Mikhailov, A. V. and Schlegel, K., Self-consistent modeling of the daytime electron density profile in the ionospheric F-region, Ann. Geophysicae, 15, 314-326, 1997.

Mikhailov, A. V. and Schlegel, K., Physical mechanism of strong negative storm effects in the daytime ionospheric F2 region observed with EISCAT, Ann. Geophysicae, 16, 602-608, 1998.

Mikhailov, A. V. and K. Schlegel, A self-consistent estimate of $\mathrm{O}^{+}+\mathrm{N}_{2}$ rate coefficient and total EUV solar flux with $\lambda<1050 \AA$ using EISCAT observations. Ann. Geophysicae, 18, 1164, 2000.

Nusinov, A. A., Models for prediction of EUV and X-ray solar radiation based on 10.7-cm radio emission., Proc. Workshop on Solar Electromagnetic Radiation for Solar Cycle 22, Boulder, Co., July 1992, Ed. R. F. Donnely, NOAA ERL. Boulder, Co., USA, 354-359, 1992.

Oliver,W. L., Hot oxygen and the ion energy budget, J. Geophys. Res., 102, 2503-2511, 1997.

Pavlov, A. V., Rate coefficient of $\mathrm{O}^{+}$with vibrationally excited $\mathrm{N}_{2}$ in the ionosphere, Geomag. i Aeronom., 26, 166-168, 1986 (in Russian).

Pavlov, A. V. and Buonsanto, M. J., Comparison of model electron densities and temperatures with Millstone Hill observations during undisturbed periods and the geomagnetic storms of 16-23 March and 6-12 April 1990, Ann. Geophysicae, 15, 327-344, 1997.

Pavlov, A. V., Buonsanto, M. J., Schlesier, A. C., and Richards, P. G., Comparison of models and data at Millstone Hill during the 5-11 June 1991 storm, J. Atmos. Solar- Terr. Phys., 61, 263-279, 1999.

Richards, P. G. and Torr, D.G., Ratios of photoelectron to EUV ionization rates for aeronomic studies, J. Geophys. Res., 93, 40604066, 1988.

St.-Maurice, J.-P., and Schunk, R. W., Ion velocity distributions in the high-latitude ionosphere, Rev. Geophys. Space Phys., 17, 99134, 1979.

Torr, M. R., Torr, D. G., Ong, R. A., and Hinteregger, H. E., Ionozation frequencies for major thermospheric constituents as a function of solar cycle 21, Geophys. Res. Lett., 6, 771-774, 1979.

Waldteufel, P, Combined incoherent scatter F1 region observations, J. Geophys. Res., 76, 6995-6999, 1971. 